\title{
Experimental Performance Analysis of Triple Tube Heat Exchanger with Dimple Tubing
}

\author{
Ganesh V. Wafelkar* and L. V. Kamble ${ }^{2}$ \\ ${ }^{1}$ DYPSOEA Ambi Talegaon, Heat Power Engineering, Savitribai Phule Pune University, Maharashtra, India \\ ${ }^{2}$ Mechanical Engineering Department of DYPSOEA Ambi Talegaon, Savitribai Phule Pune University, Maharashtra, India \\ Accepted 15 June 2016, Available online 20 June 2016, Special Issue-5 (June 2016)
}

\begin{abstract}
The experimental performance analysis of triple concentric heat exchanger are presented with reference to a double tube heat exchanger. The problem corresponding todouble tube heat exchangeris that it occupies larger tube length and space. To overcome this, a modified version of double tube heat exchanger is developed which is a triple tube heat exchanger. Triple tube heat exchanger provide larger heat transfer area per unit length of heat exchanger as compared to double tube heat exchanger. To enhance the effectiveness dimples have been made on the middle tube. The fluid used is water. Hot water will flow through the middle annular space while cold fluid will flow through the inner tube and outer annular space. The study is carried out to determine the effectiveness of triple tube heat exchanger with dimple tubing. Experimental investigation is carried out for different flow rate of cold \& hot fluid. Relationship between different performance parameters such as Nusselt number, Prandtls number, friction factor and Heat exchanger effectiveness also presented.
\end{abstract}

Keywords: Triple tube, Heat exchanger, dimples tubing

\section{Introduction}

With increasing consumption rate of energy, there is continuous growth in increasing the performance of Heat exchanger. Heat exchanger is defined as a device which transfer heat from hot fluid and cold fluid, but while transferring heat it must be with maximum rate and minimum capital cost. Heat exchangers are mostly used devices in many areas of the industries such as processing of material, food preparation refrigerators, radiators for space vehicles, automobiles \& air conditioning etc. Heat exchangers have several industrial and engineering applications. There are several kinds of heat exchangers are used in industry such as plate type heat exchanger, shell and tube heat exchanger, double pipe heat exchanger, helical tube heat exchanger etc. Double tube heat exchanger is conventionally used because of its cheaper cost and simple construction. But it occupies more space. To resolve this problem a new heat exchanger was introduced i.e. triple tube heat exchanger. It provides additional flow passage with compact design and greater heat transfer area per unit length of heat exchanger as compared to the double pipe heat exchanger. Dimple tubing is also introduced to enhance the heat transfer. Experimental study is carried out to find the effectiveness of triple tube heat exchanger.

*Corresponding author: Ganesh V. Wafelkar
Dimples on the tube surface can significantly increase the heat transfer rate. Introduction of dimples on the tube surface can increase surface area available for heat transfer. Also it reduces the hydrodynamic resistance of fluid flow over the surface by disturbing hydrodynamic boundary layer. Also the vortices formed inside the dimples results in thinning and disturb thermal boundary layer. These two effect ultimately results in heat transfer enhancement.

\section{Literature Review}

Theoretical study of triple tube heat exchanger conclude that various factors are affecting the performance of triple tube heat exchanger. In triple tube heat exchanger there is saving of considerable amount of space as well as material as compared to double pipe heat exchanger. Heat transfer rate are affected by number of fins, fin length and fin thickness. Triple tube fouling occurred greater extend toward the outlet and with the increase in time (Dharmikumar A. Patel, et al,2014).

An experimental study on one modification of triple tube heat exchanger which is triple $U$ tube heat exchanger. It is found that heat transfer rate of triple $U$ tube heat exchanger is greater than conventional model. The model is compact and unique one. This U tube design can also be implemented to double pipe heat exchanger. The implementation may result in high heat transfer rate (N. R. Parthasarathy, et al,2015). 
A numerical analysis is done on sizing of triple tube heat exchanger. During this analysis they compared triple tube heat exchanger with double tube heat exchanger for same heat transfer rate. For this, all input parameter same for both heat exchanger. It was found that length of triple tube heat exchanger was less as compared with double pipe heat exchanger. The analysis can be used for determining the dimension size of triple tube heat exchanger. It is also concluded that the triple pipe heat exchanger provide better heat transfer efficiencies per unit length of heat exchanger as compared to double pipe heat exchanger (TejasGhiwala, et al,2014).

A computational simulation of triple tube heat exchanger is carried out \&found that heat transfer occurring between three fluids at different temperature. They assumed that outer tube is thermally isolated from surrounding. It is considered as hot water in middle space which cold water and normal water in inner and outer space. Different graphs showing variation of temperature with various parameters such as length, Reynolds number etc. Finally it is found that heat transfer most likely or predominantly takes place between hot fluid and cold fluid because of the greater temperature difference between them irrespective of mass flow rate (Vishwa M. Bahera, et al,2014).

In design and analysis of triple tube heat exchanger with fins, it is found that fins provide greater extent of heat transfer in the tubing. But the fin size should be optimum so that it can allow maximum heat transfer. It was found that at particular fin height the effectiveness and efficiency is maximum is $72 \%$. Hence more compact design can be implemented to achieve desired effectiveness (Rajasekar k, et al)

In the study of the effect of dimpled tube in pipe in pipe heat exchanger, comparision was made between the flows over plane tube as well as dimpled tube. It is found that when the Reynolds number varied from 2900 to 6000 the Nusselt number with dimpled tube where greater than $30-40 \%$ than with plane tube. Also the convective heat transfer coefficient has slightly increased when we use dimpled tube. Also the effectiveness of heat exchanger with dimpled tube was $37 \%$ greater than effectiveness of heat exchanger with plane tube (Yogesh D. Banekar, et al,2015)

Comparative study of 4 types of dimpled tube with plane tube is carried out \& the inlet temperature as well as the mass flow rate of both hot and cold fluid is varied. It correlate heat transfer to the geometry of the dimple. It is concluded that convective heat transfer coefficient is inversely proportional to depth of the dimple. Also as the dimple diameter or depth decreases significant increase in Nusselt number is observed (Vilas Apte, et al,2015).

Various type heat transfer enhancement process was studied. Swirl generation is one of future scope method heat transfer enhancement. Both by active and passive method give good heat transfer rate as compared with other type methods. It is conveyed that swirl generation effectively increases the heat transfer rate as well as reduces boundary layer generation which may result low pumping power (Shekhar S. Babar, et al,2015).

\section{Experimental Setup}

Experimental setup comprises of 3 tubes which are concentrically fitted into each other. First tube is of copper and of ID $16 \mathrm{~mm}$, OD $19 \mathrm{~mm}$ and length 800 $\mathrm{mm}$. Second tube is of aluminium with ID $32 \mathrm{~mm}$, OD38 $\mathrm{mm}$ and length $750 \mathrm{~mm}$. Third tube is of mild steel with ID $44 \mathrm{~mm}$, OD $48 \mathrm{~mm}$ and length $650 \mathrm{~mm}$. Also for the flow measurement 3 rotameters(Acrylic, 0 $600 \mathrm{LPH}$ )are used for 3 concentric tubes for better control over discharge. Also 2 separate reservoir for hot water and cold water of 64 liter each. One pump (Centrifugal self-primed pump, 900 LPH, closed impeller) is used for flow creation of hot water and one pump is used for flow creation of cold water. For heating water, geyser is used. Water first passes through pump and then through geyser where it get heated. Thermocouple sensor (K-type, range $0{ }^{\circ} \mathrm{C}$ to $1260{ }^{\circ} \mathrm{C}$ ) are fitted to each inlet and outlet of each tube for measuring temperature and are connected to the temperature indicator. Second tube used is of aluminium and comprises of 2 dimples over it. These two dimples are made by using hammering on the tube. More dimples may destroy the tube in these cases so it is limited to have number of dimples only 2 . At various position brass valves are provided to adjust in the tubes whose measurement is done through rotameters. Also there is bypass to both pump provided with a valve so that low flow can be obtained by adjusting the bypass valve.

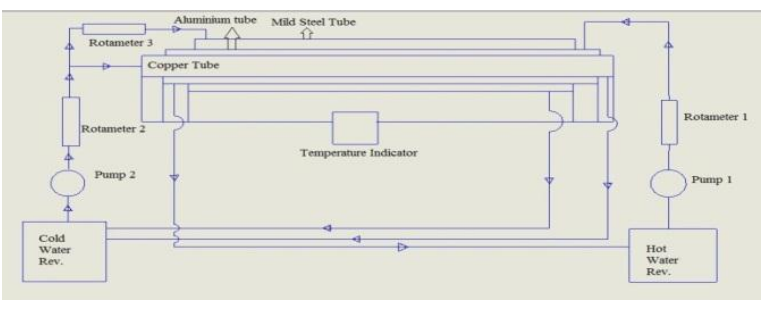

Fig.1Line diagram of Setup

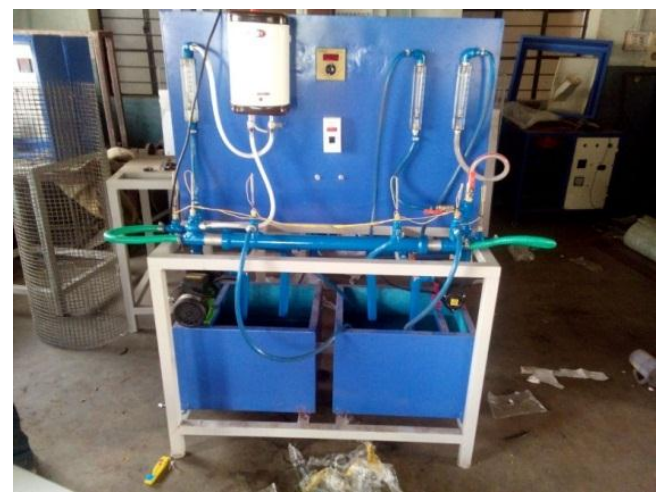

Fig. 2 Photograph view of Experimental Setup 


\section{Experimental Procedure}

Testing is carried out by keeping hot water flow rate constant and varying cold water flow rate for different flow rate of hot water flowing through inner annulus. The flow rates of hot \& cold water are controlled by using the valves assigned for each concentric tube. Assumption was made that pressure drop along the flow of fluid is negligible. For hot water flow rates are selected as: $150 \mathrm{LPH}, 200 \mathrm{LPH}, 250 \mathrm{LPH}, 300 \mathrm{LPH} \&$ for cold water flow rates are $240 \mathrm{LPH}, 300 \mathrm{LPH}, 360 \mathrm{LPH}$, 420 LPH. After achieving steady state various temperature are recorded and according to the various procedures effectiveness is calculated. Also the flow in both tubes through which cold water is flowing is kept constant.

\section{Result \& Discussions}

For various combination of flow rates of hot \& cold fluids observations are noted \& different results are plotted.

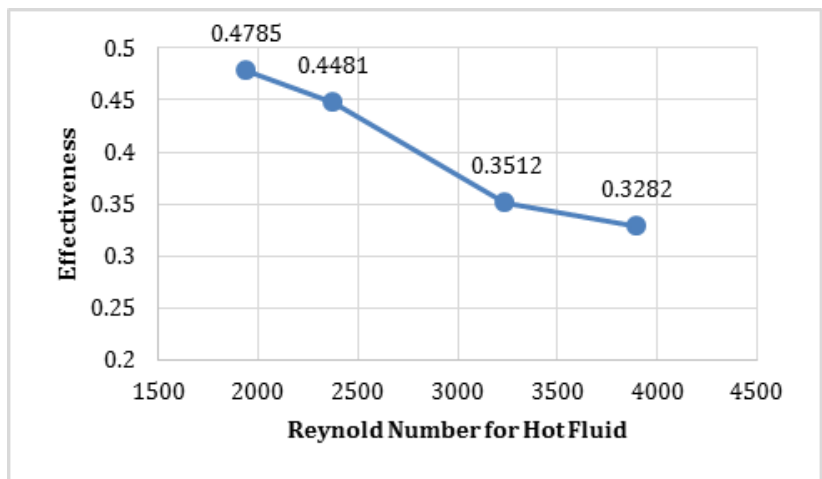

Fig. 3Effectiveness Vs Reynolds Number (Hot Fluid)

Fig. 3 shows the variation of effectiveness with respect to Reynolds number (hot fluid) for counter flow. From fig. it is observed that effectiveness increases with decrease in Reynolds number (hot fluid). Values of effectiveness vary from 0.3282 to 0.4785 . Maximum value of Effectiveness is 0.4785 obtained at Reynolds number 1944.9454. Low Reynold number ensures maximum period of contact between the flowing fluids (hot \& cold fluid).

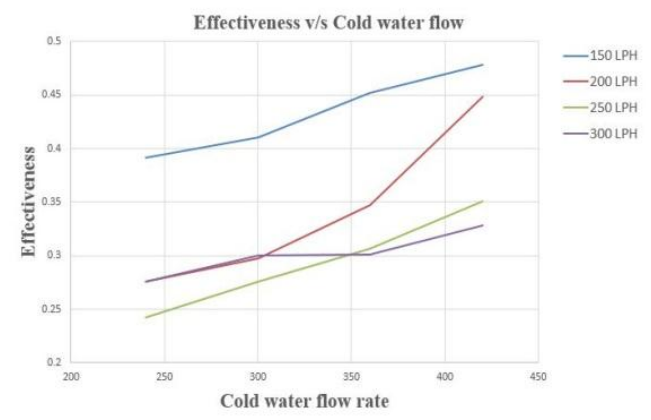

Fig. 4 Effectiveness Vs Cold Water Discharge
The effectiveness for various flow rates of cold water are determined. Fig. 4 shows variation of effectiveness with cold fluid flow for various hot water flow rates. The effectiveness goes on increasing as the cold water flow increases.

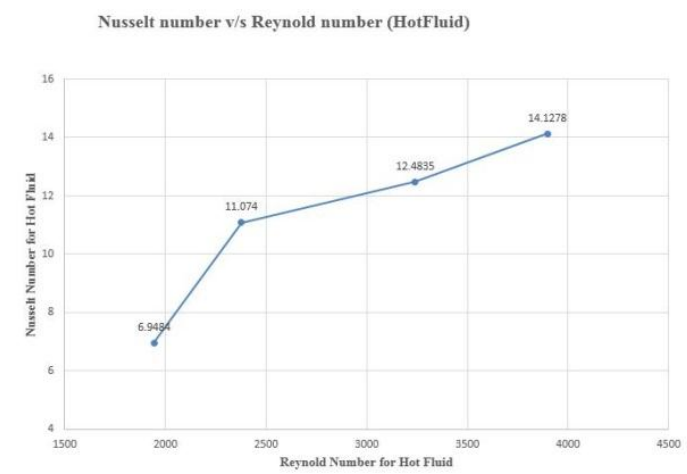

Fig. 5 Nusselt number Vs Reynolds Number (Hot Fluid)

Fig. 5 shows variation of Nusselt number with Reynolds number. Both of which are calculated for hot fluid flow. It shows that as the Reynolds number increases with Nusselt number. This is because as flow rate increases heat transfer increases.

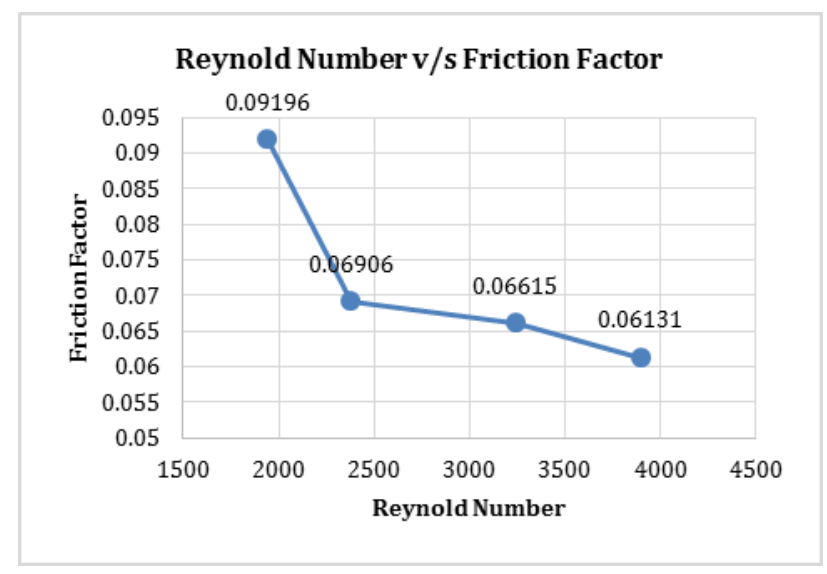

Fig. 6 Reynolds Number (hot fluid) Vs Friction Factor

Fig. 6 shows the variation of Friction factor with respect to Reynolds number for counter flow. From fig it is observed that Friction factor decreases with increase in Reynolds number. Values of Friction factor vary from 0.06131 to 0.09196 . Minimum value of Friction factor is 0.06131 obtained at Reynolds number 3897.7714.

\section{Conclusions}

Following conclusions were observed during these experimentation:

1. It is found that for the same Reynolds number effectiveness of triple tube heat exchanger is $60 \%$ more than double tube heat exchanger.

2. From the experimental data we found that Nusselt number is 1.25 times of predicted Nusselt number. 
3. Increasing effectiveness from 0.27 to 0.5 with respect to varying mass flow rate of cold water at same range of ' $\mathrm{Re}$ ' varies from 1500 to 4500 .

4. Friction factor on hot fluid side is decreases as ' $R e^{\prime}$ increases and hence pumping power is reduced.

5. Hence from the above discussion we conclude that triple tube HEX is suitable for all industrial as well as automotive vehicles(it depends on temperature range). .

\section{Future Scope}

Triple tube concentric heat exchanger performance analysis is to be carried out by using Nano fluid mixed with cold water for different concentrations \& similar results will be discussed.

\section{References}

Dharmikumar A. Patel, V. D. Dhiman, Jigensh Patel (2014), CFD analysis of triple concentric tube heat exchanger ,International Journal for Scientific and Research Development, Vol. 2, 10, 729-732.

N. R. Parthasarathy, S. Yogeswari (2015), Design and Analysis of Triple U Tube Heat Exchanger, International Journal of Emerging Technology in Computer Science \& Electronics, Vol. 12, 7, 253-256.
Tejas M. Ghiwala, V. K. Matawala (2014), Sizing of triple concentric pipe heat exchanger, International Journal of Engineering Development and Research, Vol. 2, 1683-1692.

Vishwa M. Behra, D. H. Das, AyusmanNayak (2014), Numerical analysis of triple tube heat exchanger using ANSYS, International Journal for Scientific \& Engineering Research, Vol. 5, 11, 1226-1231.

Rajasekar. K., Palanisamy S., Design and Analysis Of Trible Tube Heat Exchanger With Fins. ,IOSR Journal of Mechanical and Civil Engineering, 01-05, 1-5.

Yogesh D. Banekar, Shashank Ram Bhegade, Mayur V. Sandbhor (2015), Dimple Tube Heat Exchanger, International Journal for Science, Engineering \& Technology Research, Vol.4, 5, 1632-1635.

Vilas Apte, S. L. Borse (2015), Heat Transfer Enhancement in Dimpled Tube, International Journal of Scientific Research \& Development, Vol.3, 3, 3192-3195.

Shekhar S. Babar, Kiran D. Devade (2015), Heat Transfer Enhacement in Pipe in Pipe Heat Exchanger with Swirling Flow: Review, International Journal for Scientific Research \& Development, Vol.3, 3, 990-995.

M. T. Naik, Syed Sha Fahad, L. Syam Sunder, Manoj K. Singh (2014), Comparative study on thermal performance of twisted tape \& wire coil inserts in turbulent flow using $\mathrm{CuO} /$ water Nanofluid, Experimental Thermal and Fluid Science, 57, 65-76.

B. N. Kharad, G. P. Bhagat, R. M. Ghodke, A. P. Avhad (2014), Heat Transfer EnhacementUsing Nano fluids- An Overview, IJIRSET, Vol.3, 4, 105-109. 